\title{
Reminder: Tetralogy of Fallot is not just a right-sided cardiac problem
}

\author{
William M. DeCampli, MD, PhD
}

\author{
From the Department of Pediatric Cardiothoracic Surgery, Arnold Palmer Hospital for Children, Orlando, Fla; and \\ Department of Surgery, University of Central Florida College of Medicine, Orlando, Fla. \\ This study did not require funding. \\ Disclosures: Author has nothing to disclose with regard to commercial support. \\ Received for publication Sept 15, 2018; accepted for publication Sept 17, 2018 \\ Address for reprints: William M. DeCampli, MD, PhD, Pediatric Cardiothoracic Surgery, Arnold Palmer Hospital \\ for Children, 83 W Miller St, Orlando, FL 32813 (E-mail: William.decampli@orlandohealth.com or William. \\ decampli@ucf.edu). \\ J Thorac Cardiovasc Surg 2018;156:2237-8 \\ $0022-5223 / \$ 36.00$ \\ Copyright (c) 2018 by The American Association for Thoracic Surgery \\ https://doi.org/10.1016/j.jtcvs.2018.09.049
}

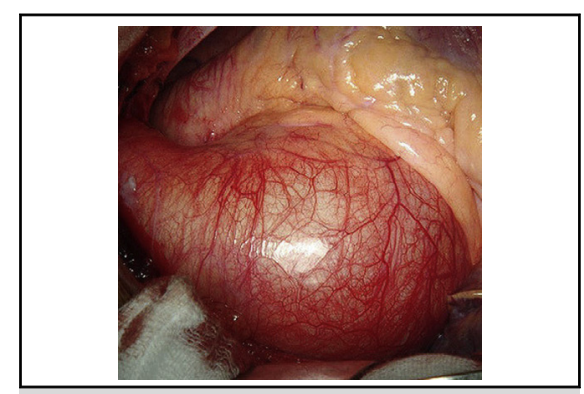

Keep an eye on the aortic root after tetralogy of Fallot repair!

\section{Central Message}

The dynamics of the aortic root in tetralogy of Fallot is abnormal even after repair and even if the root is not dilated. This finding raises the possibility of late left-sided circulatory problems.

See Article page 2239. less the root becomes frankly aneurysmal. Limiting our exposure to patients in the first few decades of life, we only infrequently see clinical complications of the enlarged TOF aorta. We treat it more as a curiosity.

There is, however, additional, hidden pathology in the TOF root. In this issue of the Journal, Schäfer and colleagues $^{2}$ report 4-dimensional flow magnetic resonance imaging measurements of aortic size, distensibility, and wall shear stress (WSS) in a small cohort of adolescents who underwent repair of TOF in infancy. In their comparison with an age-matched control group, Schäfer and colleagues ${ }^{2}$ found the following: (1) aortic root size did not differ between the groups, (2) aortic distensibility was decreased, (3) WSS was elevated, and (4) helical flow was qualitatively increased.

Why are these observations important? WSS and degree of helical flow are primarily determined by the velocity field of the inflow to the aorta and are thus generated in the left ventricle (LV), the LV outflow tract, and the aortic valve. Elevated WSS and helical flow are transduced by endothelial cells, which signal the vessel wall to thicken and increase in diameter. Changes in the architecture of the wall decrease distensibility. Although increased diameter may tend to decrease WSS, decreased distensibility tends to increase WSS. ${ }^{3-5}$ The interplay of these factors is complex. This interplay and normal changes with somatic growth make the evolution of the aortic root in TOF uncertain but potentially concerning. Perhaps decades later, the root may again begin to dilate and become aneurysmal. Decreased aortic distensibility will increase LV afterload, blunt normal small vessel pulse pressure, and compromise coronary perfusion, ultimately resulting in an increased risk of cardiovascular morbidity and mortality associated with the left-sided circulation.

What is the origin of this problem? Interestingly, the aortic valve and root are already dilated at birth in TOF. Aortic specimens obtained at TOF repair at a median age of 6 months show abnormal fibrosis in $45 \%$ of patients. In fact, dilation is evident in the second-trimester fetus. Recently, Taketazu and coworkers ${ }^{7}$ reported that aortic distensibility was significantly less in 22- to 39-week fetuses with TOF than in normal fetuses (Figure 1). Aortic root pathology is not limited to TOF but also occurs in other conotruncal anomalies, including double-outlet right ventricle, truncus arteriosus, and transposition of the great arteries. $^{8}$ These observations suggest that at least the predilection for root dilation is intrinsic to conotruncal anomalies through abnormal genetic signaling during heart formation and development. ${ }^{9}$ On the other hand, early repair of TOF is associated with lack of progression, or even regression, of root dilation. Because WSS is primarily determined by the inflow velocity field, perhaps repair alters this velocity field and thus the impact of WSS on the root. The key finding of the study of Schäfer and colleagues ${ }^{2}$ is that repair does not completely normalize WSS and distensibility. What remains is to determine the precise reason for the 


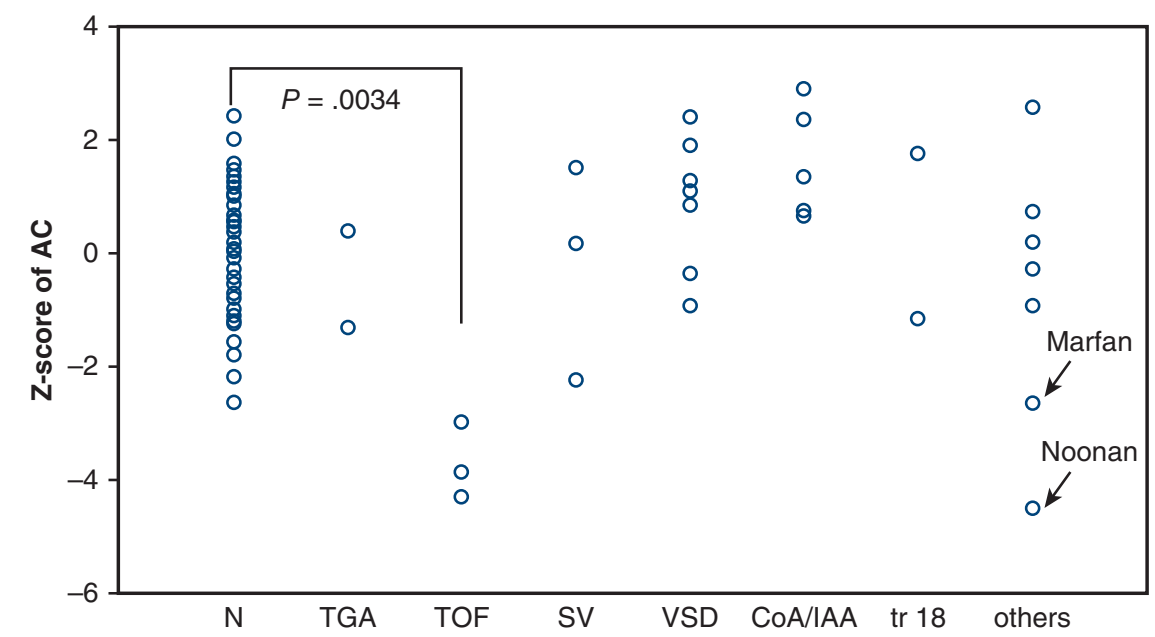

FIGURE 1. Comparison of $z$ score of aortic compliance $(A C)$ between normal fetuses $(N)$ and fetuses with congenital cardiac anomalies. Compliance is significantly decreased in fetuses with tetralogy of Fallot $(T O F)$ relative to that of normal fetuses. Arrows indicate aortic compliance of sample patients with Marfan and Noonan syndromes. TGA, Transposition of the great arteries; $S V$, single ventricle; VSD, ventricular septal defect; CoA/IAA, coarctation of the aorta/interrupted aortic arch; tr18, trisomy 18 with ventricular septal defect. (Used with permission from Elsevier. ${ }^{7}$ )

elevated WSS in this cohort-is it the underlying persistent decreased distensibility, or is it a persistently abnormal inflow velocity field, resulting from the patched anterior malalignment defect, or an interaction of the LV and the right ventricle? Detailed computational modelling may be required to answer this question. Likewise, measurements were made only at one time per patient. The timedependent behavior of the root will lend further to our understanding of this phenomenon, as well as its potentially significant clinical impact. TOF is not just a right-sided problem.

\section{References}

1. Mongeon FP, Gurvitz MZ, Broberg CS, Aboulhosn J, Optowsky AR, Kay JD, et al. Alliance for adult research in congenital cardiology (AARCC). Aortic root dilatation in adults with surgically repaired tetralogy of Fallot: a multicenter crosssectional study. Circulation. 2013;127:172-9.

2. Schäfer M, Browne LP, Morgan GJ, Barker AJ, Fonseca B, Ivy DD, et al. Reduced proximal aortic compliance and elevated wall shear stress after early repair of tetralogy of Fallot. J Thorac Cardiothorac Surg. 2018;156: 2239-49.

3. Papaioannou TG, Stefanadis C. Vascular wall shear stress: basic principles and methods. Hellenic J Cardiol. 2005;46:9-15.

4. Glasser SP, Arnett DK, McVeigh GE, Finkelstein SM, Bank AJ, Morgan DJ, et al. Vascular compliance and cardiovascular disease: a risk factor or a marker? Am J Hypertens. 1997;10:1175-89.

5. Zeng D, Boutsianis E, Ammann M, Boomsma K, Wildermuth S, Poulikakos D. A study on the compliance of a right coronary artery and its impact on wall shear stress. J Biomech Eng. 2008;130:041014.

6. François K, Creytens D, De Groote K, Panzer J, Vandekerckhove K, De Wolf D, et al. Analysis of the aortic root in patients with tetralogy of Fallot undergoing early repair: form follows function. J Thorac Cardiovasc Surg. 2014;148:1555-9.

7. Taketazu M, Sugimoto M, Saiki H, Ishido H, Masutani S, Senzaki H. Developmental changes in aortic mechanical properties in normal fetuses and fetuses with cardiovascular disease. Pediatr Neonatol. 2017;58:245-50.

8. Dearani JA, Burkhart HM, Stulak JM, Sundt TM, Schaff HV. Management of the aortic root in adult patients with conotruncal anomalies. Semin Thorac Cardiovasc Surg Pediatr Card Surg Annu. 2009;122-9.

9. Seki M, Kuwata S, Kurishima C, Nakagawa R, Inuzuka R, Sugimoto M, et al. Mechanism of aortic root dilation and cardiovascular function in tetralogy of Fallot. Pediatr Int. 2016;58:323-30. 